\title{
Humedal El Cortijo: Evidencia sobre la acción colectiva en defensa del ambiente en Santiago de Cali
}

\author{
Angélica Hernández-Morales ${ }^{1}$ \\ Universidad del Valle, Cali, Colombia \\ hernandez.angelica@correounivalle.edu.co \\ https://orcid.org/0000-0002-7866-1517
}

Angie Karina Rengifo-Fernández

Universidad del Valle, Cali, Colombia

angie.fernandez@correounivalle.edu.co

https://orcid.org/0000-0002-3254-9626

\begin{abstract}
Juan Pablo Jiménez-Herrera ${ }^{3}$
Universidad del Valle, Cali, Colombia

juan.p.jimenez@correounivalle.edu.co

https://orcid.org/0000-0002-5957-1495
\end{abstract}

Leydy Johana Narvaez-Ovalle ${ }^{4}$

Universidad del Valle, Cali, Colombia

leydy.j.narvaez@correounivalle.edu.co

https://orcid.org/0000-0002-2422-6245

González, L., Mosquera, J., Garbiras, A., Palau, A. y Escobar, G. (2019). Intervención del bosque seco tropical y humedal El Cortijo Cali Lucha por la defensa del humedal y relicto boscoso por la comunidad. Cali, Colombia: Poemia.

En los dos últimos años, los habitantes de Cali, o al menos una parte de ellos, han estado al tanto de un conflicto sin precedentes por el mal manejo de los recursos ambientales y la afectación que esto genera en la comunidad del sur de Cali, específicamente en el sector conocido como Valle del Lili, por colindar con el río Lili y la zona del bosque seco tropical y humedal El Cortijo. Para los habitantes del sector, el Humedal es de gran valor y han desarrollado un gran sentido de pertenencia respecto del mismo. Si bien el humedal no ofrece beneficios económicos para quienes residen en la zona, como lo indica el texto, sí les brinda una variedad de servicios ecosistémicos, tales como: mejorar la calidad del aire, regular la temperatura, paisajes con valor estético, espacios culturales

\footnotetext{
Estudiante del Programa de Economía.

Estudiante del Programa de Economía.

Estudiante del Programa de Economía.

Estudiante del Programa de Economía.
}

(c) (i) Este trabajo está bajo la licencia Creative Commons Attribution 3.0

¿Cómo citar este artículo? / How to quote this article?

Hernández-Morales, A., Rengifo-Fernández, A. K., Jiménez-Herrera, J. P. y Narvaez-Ovalle, L. J. (2020). Humedal El Cortijo: Evidencia sobre la acción colectiva en defensa del ambiente en Santiago de Cali. Sociedad y economía, (40), 163-166. https://doi. org/10.25100/sye.voi40.9177voi40.9177 
y de recreación. Así mismo, se une al corredor ambiental que conecta a la ciudad, el cual es primordial para la migración de aves.

El objetivo de esta iniciativa de memoria colectiva, como bien mencionan los autores, es servir de insumo para la investigación social e histórica de las disputas ambientales, recopilando y dejando constancia de la lucha por proteger el corredor ecológico y biocultural del río Lili. Se construyó a partir de testimonios y narración documental sobre las acciones y actividades comunitarias desarrolladas a lo largo de estos dos años. Lo valioso del texto se puede encontrar en la narrativa que se cuenta desde la perspectiva de los actores principales: la comunidad, los ciudadanos habitantes del sector que se vieron sorprendidos y molestos al ver que empezaban a llegar todos los elementos necesarios para la destrucción del humedal. El término "maldesarrollo" se acuña a partir del aporte de una habitante del sector, haciendo referencia al actuar anti ambientalista que ejercen las entidades del estado y el mercado bajo el discurso del llamado "desarrollo".

Esta obra, recolección de memorias, es también una rica descripción técnica sobre las condiciones biofísicas de la zona, que se realiza gracias a dos colaboradores con conocimientos en el área ambiental: Luis Antonio Gonzáles Escobar y Germán Escobar Berón. Se muestran las diferentes especies de aves, insectos, flores, plantas y todos los ecosistemas que dependen del equilibrio de la zona. Además, traen a colación la crítica al modelo de desarrollo que está en juego y que está impulsando este acontecimiento. La expansión de la ciudad versus la conservación de un ecosistema complejo, que tiene importantes implicaciones como corredor ecológico y puente biológico.

El conflicto se originó cuando, de manera abrupta e unilateral, Metrocali invadió el espacio público aledaño a la zona residencial, con herramientas y maquinaria de construcción pesada, perturbando la tranquilidad del sector. Las obras se piensan ejecutar con el fin de construir la terminal sur en el sector de Valle del Lili. Este proyecto se gestionó, desde el principio, sin ningún tipo de socialización con la comunidad. Los habitantes habían presentado varias solicitudes con antelación para realizar obras como polideportivos, iglesias o canchas de fútbol que fueran útiles para la recreación, respetando los límites del humedal. Todas estas peticiones fueron denegadas sin justificaciones claras. No fue sino hasta la presencia de los instrumentos de construcción que la comunidad se enteró para qué habían destinado la zona.

Para entender el conflicto es primordial vislumbrar las posibles afectaciones en el lugar. El proceso en su fase inicial de construcción provocó la destrucción de vías y la tala de más de 250 árboles sembrados incluso por la misma comunidad. El humedal El Cortijo es una zona de hundimiento que alberga una variedad de 150 especies, de las cuales 50 corresponden a árboles de bosque seco. Esta zona ofrece otras labores, como la protección de la ribera del río Lili. La vegetación en esta zona tiene una adaptación a las inundaciones, por lo cual no escasea nunca el agua, además de ofrecer una variedad de servicios ecosistémicos, antes mencionados. Igualmente, de acuerdo a estudios encargados a la Universidad del Valle, se encontró que las obras afectarían negativamente el humedal, en niveles bastante significativos, lo que implicaría la muerte del Humedal El Cortijo y una gran pérdida de biodiversidad para el país. Sin embargo, en el mismo estudio se resalta que con una reubicación podría conservarse el humedal, lo que para los habitantes resultó contradictorio.

Ante esta situación, la comunidad decide actuar y pasa de un estado pasivo de observación e indignación a formar un tejido social y una organización para afrontar de manera activa el problema que recae sobre este bien común. A partir del reconocimiento del atropello ambiental y jurídico que se ejerce sobre su territorio, los residentes emprenden toda una lucha por el reconocimiento de la naturaleza como sujeto de derecho, y del papel que le corresponde a la ciudadanía en la toma de decisiones. La comunidad se pronunció buscando recursos legales, y vías de hecho pacífica como la protesta. No obstante, el proyecto iba a seguir a costa de todo, lo que impulsó a que se unieran y se alzara una 
carpa en la zona de construcción, que más adelante se convertiría en el símbolo de su lucha, a la cual llamaron "La carpa de la resistencia". Esta se convierte en un espacio de diálogo y planificación de actividades de acción colectiva, como caravanas, plantones, marchas, velatones, siembra de árboles y kermes. Es, sin duda, un precedente histórico en la organización y cohesión social de una comunidad en defensa del territorio (al menos en la ciudad de Cali).

Si bien muchos de los detractores de esta manifestación aluden a intereses personales de ciudadanos que se afectaron directamente por el ruido, la contaminación y la desvalorización de sus propiedades, lo que en realidad se refleja es el amor por la naturaleza y el sentido de pertenencia hacia lo que defienden. La concientización de la importancia del ecosistema condujo a un evento sin precedentes y que, lejos de ser criticado, deber ser apoyado. Como se mencionaba en el texto, el trasfondo real de esta discusión es la confrontación de dos modelos de desarrollo que van en contravía uno del otro, muestra de que cada día se están haciendo más visibles las problemáticas ambientales y la sociedad está siendo más consciente, en el corto plazo, de las implicaciones de su hábitat.

Alrededor de los procesos legales relacionados con la construcción de esta obra, se encontraron diferentes inconsistencias. Los abogados organizados con la comunidad hallaron 16 fallas legales en cuanto a la omisión de las instituciones y sus normas, respecto a la otorgación, validación, tramitación y cualquier acción relacionada con la construcción de predios dentro del ecosistema El Cortijo, excluyendo a los habitantes del sector y tomando acciones arbitrarias e ilícitas, sin cumplir con estudios ni facultades legales correspondientes para intervenir el humedal. Es claro que la CVC viola el artículo 40 de la ley 734 de 2002, al ser accionista de la Terminal de Transporte de Cali, a quien se adjudica la licencia y contrato por parte de esta entidad. Por ende, tiene un claro conflicto de intereses, incurriendo en delito.

De igual forma, la propiedad legal del lote se encuentra en pleito y es uno de los aspectos más importantes y turbios en este conflicto. Aún no se logra comprender cómo se desarrolló la compra del predio, ya que esta área contaba con estudios en los que se demostraba la existencia de importantes características ambientales como un humedal, un relicto boscoso, una acequia interna y unos nacimientos de agua. Actualmente, el lote sigue sin ser propiedad ni del municipio ni de Metrocali, y alrededor de la tenencia y dominio de la tierra hay un conflicto jurídico en curso que ha venido vislumbrando muchos vicios legales y contractuales. El abogado Jair Zapata indica una serie de irregularidades legales en relación al rol de la CVC, ya que esta entidad debía haberse pronunciado como impedido de emitir permisos ambientales, puesto que salió a la luz pública de que son también parte accionista del proyecto $y$, por lo tanto, se presenta un conflicto de intereses evidente ante esta situación.

La lectura del texto deja un sinsabor y obliga a plantear la pregunta ¿cuáles aspectos se están priorizando en los mecanismos legales para la mitigación del daño ambiental y la protección del mismo? Si bien existen, como muestra el texto, múltiples mecanismos legales para la defensa y amparo del medio ambiente, así como de participación ciudadana, vemos que la forma de gobierno en el país está profundamente viciada, vacía e incorrecta, con múltiples intereses en común que no piensan más allá del lucro, y que, como han hecho históricamente, pretenden pasar por encima del ciudadano, con sus máquinas que dicen traer el desarrollo. $\mathrm{Si}$ no podemos contar con estas instituciones formales, ¿qué nos queda? La respuesta la emite la propia comunidad: la acción popular. De hecho, vimos cómo, excepcionalmente, las señoras de la comunidad lideraron la toma pacífica del humedal, se amarraron a los árboles que iban a ser talados y arriesgaron sus vidas por la vida de los que no tienen voz.

En el texto, encontramos lo siguiente: “...de acuerdo con lo anterior, el estado del conocimiento del bosque seco tropical en Colombia es pobre dado que son pocos los lugares donde existen inventarios completos y la poca existencia de información de historia natural 
y dinámica del bosque" (p. 27). Lo cual es una pena para el empoderamiento de la ciudadanía con su territorio y el medio ambiente, necesidad inminente a nivel mundial para la supervivencia de nuestra especie. Es interesante y valioso cuando el texto narra cómo en el Alférez real y la María (novelas clave en la literatura vallecaucana) se narra la inmensa biodiversidad y capacidad hídrica de la que gozaba el Valle del Cauca, y cómo, a partir de la urbanización, todo eso se ha destruido, conservando medianamente algunas características medioambientales como el Lago de la Babilla o el río Lili. Hoy debemos hacerle frente al maldesarrollo y tomar el papel como comunidades del rumbo de nuestras vidas, mediante la acción popular y el uso esperanzado de lo que hoy queda de nuestras corruptas instituciones.

Es un aporte muy valioso la forma de organización que resultó de este conflicto. Además, revela que depender de la voluntad de los políticos, en una sociedad profundamente enferma por la corrupción, es un grave error. Las instituciones encargadas no siempre tendrán las mejores intenciones o respetarán lo que promulgan sus funciones legales. En este caso en específico, se mostró que su decisión fue favorecerse a sí mismas. Somos nosotros, y no su disposición, los que debemos exigir un buen gobierno y un buen vivir. Esta obra es, pues, una muestra de la capacidad de organización social de las personas y el papel que desenvuelven las entidades gubernamentales en la toma de decisiones en torno a proyectos con un amplio espectro de impactos. La configuración legal e institucional permiten que personas tomen decisiones que menoscaban los derechos de las comunidades, y la acción colectiva, desde esta perspectiva, permite afrontar el conjunto de elementos que rodean estas decisiones. 